\title{
STATEMENT OF PRINCIPLES REGARDING PROPERTY AND CASUALTY LOSS AND LOSS ADJUSTMENT EXPENSE LIABILITIES
}

\author{
COMMITTEE ON LOSS RESERVES *
}

The purpose of this statement is to provide general guidelines for the use of actuaries engaged in the establishment and review of loss and loss adjustment expense reserves. It is a statement of the Casualty Actuarial Society's Committee on loss Reserves. The statement consists of three parts.

\section{Definitions \\ 2. Considerations \\ 3. Procedures}

The balance sheet of the Fire and Casualty Annual Statement includes liabilities that are not subject to precise valuation. The reserves for unpaid losses (line 1, page 3 of the Annual Statement) and the reserve for unpaid loss adjustment expense (line 2, page 3 of the Annual Statement) cannot be precisely determined in advance. These reserves must be estimated. Because of their relative size and the difficulty in achieving accurate estimates of their values, these liabilities are vitally important balance sheet items. It is important that proper actuarial and statistical procedures be employed in order to improve the likelihood of reliable reserve estimates. Without reliable reserve estimates, an accurate evaluation of the financial condition of a fire and casualty insurer cannot be accomplished.

Loss reserving involves the current financial evaluation of costs associated with future contingent events, a matter of fundamental interest to actuaries. The contingencies involved are those factors which affect the cost of future payments on insured events which have already occurred. As ratemaking is another application of the same estimating process, the actuarial methodology is similar in many respects.

The definitions in the next section apply to both loss reserves and loss adjustment expense reserves.

For the purpose of this statement the terms "loss" and "claim" will be used interchangeably.

* This is a statement, originally published in May, 1978 by the Casualty Actuarial Society's Committee on Loss Reserves. The Committee consisted of Martin Adler, James R. Berquist, Warren P. Cooper, Charles A. Hachemeister, James A. Hall, III, Harry R. Richards, William A. Riddlesworth, Richard H. Snader, Donald E. Trudeau. 


\section{DEFINITIONS}

Loss reserving procedures should operate on well defined groups of losses, such as losses arising from the exposures associated with a particular policy period, or losses resulting from accidents occurring within a particular calendar period, or losses associated with a particular coverage, or losses occurring in a particular state, and so on.

The reserve for all claims occurring on or before a certain date, called the accounting date, is evaluated as of a valuation date. The accounting date may be any date selected for an accounting or statistical purpose. The valuation date of a reserve liability is the date as of which the evaluation of the reserve liability is made. For a particular well defined group of claims, several evaluations of the reserve liability may be made as of successive valuation dates. A valuation date may occur prior to, coincident with or subsequent to the accounting date.

The total loss reserve for a well defined group of losses as of a given valuation date is the amount that must be paid in the future to settle all such losses which have occurred on or prior to a particular accounting date. The true value of the total loss reserve can only be known when all claims in the group have been finally settled. Prior to that time the value of the total loss reserve must be estimated. For a specific group of claims the insurer's estimate of the total loss reserve will very likely change from one valuation date to another.

The indicated total loss reserve is an estimate of the total loss reserve resulting from a particular loss reserving procedure or methodology. The carried total loss reserve is the amount shown in a published statement or in an internal statement of financial condition.

There are five elements of the total loss reserve:

1. case reserves,

2. the provision for future development on known claims,

3. the reopened claims reserve,

4. the provision for claims incurred but not reported,

5. the provision for claims in transit (incurred and reported but not recorded).

Although the total loss reserve is comprised of these five elements, it is not necessarily derived by specifically quantifying each of the five. Each of these reserve elements will be defined in succeeding paragraphs.

For Annual Statement purposes a division is required between known claims and claims which have been incurred but not reported (IBNR). The reserve for known claims ${ }^{1}$ represents the amount of money, estimated as of the valuation

1 The reserve for known claims is also sometimes referred to by a variety of other labels such as the "reported reserve", the "adjusted or in the process of adjustment" or the "unpaid losses excluding IBNR". 
date, that will be required for future payments on claims which have already been reported to the company. The $I B N R$ reserve represents the amount which must be provided for future payments on losses which have occurred but which have not been reported.

There is not universal agreement on the proper categorization of all of the five reserve elements between known claims and IBNR. For the purpose of this statement, the reserve for known claims will be considered to consist of case reserves, the provision for development on known claims and the reopened claims reserve. The $I B N R$ reserve will be considered to consist of the remaining elements.

The case reserve ${ }^{2}$ is defined to be the sum of the values assigned to specific claims by claim adjusters, reserves for known cases set by formula or some combination thereof. The term adjusters' estimates is used to refer to the aggregate of the estimates made by claim personnel on individual claims, based on the facts of those particular claims. Formula reserves are reserves established by formulas for groups of claims and are obtained from a process in which certain classifying information is provided, and the estimated reserve amounts are determined as responses to encoded instructions. Formula reserving may be applied to individual claims or to aggregations of claims with similar characteristics. When the formula reserving technique is applied to aggregations of claims, the formula reserve may be obtained, for example, through the use of any pertinent insurance statistics such as premium in force, earned premiums, number of policies or claim counts.

Development is defined as the difference, on successive valuation dates, between observed values of certain fundamental quantities which may be employed in the loss reserve estimation process. For example, the observed number of reported claims associated with losses occurring within a particular calendar period will very often be seen to increase from one valuation date to the next until the time arrives when all claims have been reported. The pattern of accumulating claims represents the development of the number of claims. In a similar fashion the amount of claim payments for losses occurring within a specific calendar period will also be seen to increase with successive valuation dates. In this case the pattern of accumulating payments represents the development of claim cost and is usually referred to by the term payment development.

The concept of development may also be applied to incurred losses. Incurred development is defined as the difference between estimates of incurred cost on successive valuation dates for a well defined group of claims.

With respect to known claims this statement is particularly concerned with incurred development-that is, subsequent development of cost estimates on those claims reported to an insurer on or before a specific accounting date

2 The term case reserve is occasionally used in place of the reserve for known claims, but when it is used in this sense it is a misnomer. 
which are still open on that accounting date. Incurred development on such claims can be either increasing or decreasing. An observed pattern of increasing development might indicate that initial reserve estimates were inadequate. An observed pattern of decreasing development might indicate that initial reserve estimates were redundant. In providing for the development on known claims, an attempt is made to measure development and to compensate for the anticipated reserve inadequacy or redundancy on those claims.

The reopened claims reserve is a provision for closed claims on which payments will be made after the valuation date because of circumstances not forseen at the time the cases were closed. In some instances, post-closing payments or recoveries for claims not physically reopened may be included with development on known claims.

Following typical company procedures a claim is considered to be reported when it is first recorded in the accounting records of the company. For this reason the $I B N R$ reserve can be thought of as consisting of two basic elements. The first of these elements is the provision for those claims, referred to as the "true" IBNR, whose existence is completely unknown to the company. This provision represents the normal delay which occurs in reporting losses to the company. The second element is the provision for claims in transit, which are incurred and reported but not recorded. This provision represents the additional time consumed by company recording procedures. As a practical matter it might not always be feasible to measure these two elements separately, but it is important to understand the effect company reporting procedures can have on the amount of the $I B N R$ reserve.

In the determination of the $I B N R$ reserve it is necessary to estimate the future emergence of IBNR claims. Emergence refers to claims which have already occurred but which are expected to be first observed in future reporting periods. Emergence of IBNR and development on the reserve for known claims are often not differentiated. For the purpose of this statement the use of the term development will be confined to claims which have been reported. The $I B N R$ reserve must be sufficient to cover the ultimate value of future emergence. Thus, a provision must be made in the IBNR reserve for the development which may be expected to occur on IBNR claims after they have emerged.

The loss adjustment expense reserve is the amount needed to cover all future expenses required to investigate and settle claims incurred on or before a particular accounting date, whether reported or not. Loss adjustment expense reserves should be considered separately for

1. allocated loss adjustment expenses and

2. unallocated loss adjustment expenses.

Allocated loss adjustment expenses are those expenses, such as attorneys' fees and legal expense, which are incurred in connection with and are assigned 
to specific claims. Unallocated loss adjustment expenses are all other claim adjustment expenses, such as salaries, heat, light and rent, which are associated with the claim adjustment function but are not readily assignable to specific claims.

Certain kinds of adjustment expense are not easily categorized between allocated and unallocated. Independent adjusters' fees, for example, may be classified as allocated expense if the adjusters' bills provide sufficient information to enable the insurer to associate the cost of the adjusters' services with specific claims. If, however, the bills do not provide sufficient information, the insurer must classify the expense as unallocated.

Since allocated expenses are assigned to specific claims, all of the analyses performed on loss data can also be performed on allocated loss expense data. Thus, although not required by the Annual Statement, the allocated loss adjustment expense reserve can be divided into known reserve and IBNR components. In fact, all of the concepts discussed in the preceding paragraphs, such as development and emergence, as well as each of the five elements of the total loss reserve, have similar meanings with regard to the allocated loss adjustment expense reserve.

Although the same statistical procedures do not apply to unallocated expenses, the unallocated loss adjustment expense reserve can still be divided into known reserve and IBNR components, and the concept of a particular valuation date is meaningful.

\section{CONSIDERATIONS}

Loss reserving is fundamentally concerned with the estimation of ultimate loss costs on unpaid claims.

Understanding the trends and changes affecting the data base is a prerequisite to the application of actuarially sound reserving methods. A knowledge of changes in underwriting, claims handling, data processing and accounting, as well as changes in the legal and social environment affecting the experience is essential to the accurate interpretation and evaluation of observed data and the choice of reserving methods.

The establishment and evaluation of proper reserves is considerably improved by subdividing the entire claims experience into well defined groups. Where possible, loss data which have been relatively unaffected by changes in company procedures and operations should be used. The possibility of subdividing or combining the data so as to increase its homogeneity or to minimize the distorting effects of underlying or procedural changes on the data should be fully explored.

The actuary should be conversant with the general characteristics of the insurance portfolio for which reserves are to be established. This would normally include familiarity with the contractual guarantees and obligations 
under policies in force as well as other attributes, such as deductibles, policy limits and reinsurance provisions, which may have a bearing on reserving.

\section{Homogeneity}

The actuary should strive to group together those claims exhibiting similar characteristics, such as comparable claim experience patterns, settlement patterns or size of loss distributions. For example, to the extent that the actuary is dealing with a heterogeneous product, such as commercial multiperil or miscellaneous liability insurance, consideration should be given to breaking apart these products into more homogeneous groupings. Some other examples of specific considerations regarding homogeneity are the distinction between personal and commercial risks and the distinction between primary and excess coverage.

\section{Credibility}

The degree to which consideration is given to homogeneity is related to the consideration of credibility. Credibility is increased by proper homogeneons groupings on the one hand and by increasing the number of claims analyzed within each group on the other. A group of claims should be large enough to be statistically reliable. Obtaining homogeneous groupings requires refinement and fragmentation of the total data base. Clearly, there is a point at which refinement scatters data into cells too small to provide credible development patterns. Each situation requires a fresh balancing of the considerations of homogeneity and statistical credibility. Thus, line and coverage definitions suitable for the establishment of reserves in large companies can be in much finer detail than in the case of small companies. Where a very small group of claims is involved, use of external information such as industry aggregates may be necessary.

\section{Data Availability}

It is the actuary's responsibility to assure that the necessary data for the establishment of proper reserves are available. Frequently, however, this means working within the constraints of existing information systems while more suitable data are being developed. It is also the actuary's responsibility to be sure that the claim data used in analysis of reserves is reconcilable with company financial records.

The actuary should bear in mind the form in which the final results will have to be reported to management, to regulators or to other interested parties. If reserves are established on groups of claims which are broader than the necessary reporting requirements, procedures for assigning the reserves to the required categories must be developed. 


\section{Emergence Patterns}

The delay between the occurrence of claims and the recording of claims on the books of the company depends upon both the line of business and company practices. In general, property claims are reported quickly, whereas the reporting of liability claims may be substantially delayed. A review of company claims practices should always be made to assure that correct assumptions are being made by the actuary regarding the claims process. Perhaps even more importantly, the actuary should continually review and be made aware of claims procedures and the claims handling process. Whenever a change in claims procedure can be identified, experience should be adjusted to align it with more recent claims practice.

\section{Settlement Patterns}

The length of time that it normally takes for reported claims to be settled will affect the choice of the loss reserving procedure. Lines of business for which claims settle quickly are less subject to reserve inadequacies. Claims arising under Glass coverage, for example, tend to be settled quickly, and the amount of settlement is usually close to the original estimate. On the other hand, bodily injury liability claims often require a long time to settle, even when reported immediately to the company. The ultimate amount of settlement depends on the interaction of more complex variables, such as the type and severity of the injury and the intricacies of the judicial process.

\section{Development Patterns}

In establishing reserves, substantial care should be given to reviewing the pattern of development on known cases. The company's claims procedures will affect the manner in which the case reserves change over time for any individual claim. Further, the length of time to settlement will affect the observed reserve development.

In order to correctly interpret development patterns, the actuary must also determine which reserves have been established at discounted present value, the rate of interest and the aggregate amount of discount. In ordinary circumstances if aggregate reserves have been perfectly estimated, no subsequent development will occur. If, however, such reserves have been discounted for interest, upward development will be observed equal to the aggregate amount of discount for which credit has been taken.

\section{Frequency and Severity}

The same total dollars of losses may arise from a few very large claims or from many small claims. Reserve estimates will tend to be more accurate for losses resulting from a high frequency/low severity group of claims than from a low 
frequency/high severity group of claims. Therefore much more care should be taken in analyzing low frequency/high severity groups of claims.

If the exposure for the group of claims being considered includes the potential for claims of a magnitude not seen in past experience, judgment adjustments should be made in the reserve to reflect the possibility of such claims arising.

\section{Reopened Claims Potential}

The propensity for claims, which were believed to be closed, to reopen varies substantially among lines of business. Beyond this, precedent-setting judicial opinions and liberalizing legislation can affect the reopening of claims. Company procedures will also affect the potential for claims to be reopened. A time to be alert is when operating procedures (claims, data processing, accounting, etc.) are changing or emphasis is shifting.

\section{Aggregate Limits}

For certain insurance coverages, such as products and malpractice liability, aggregate policy limits will act to restrict total potential incurred losses and therefore reserve liabilities. In revieiwng groups of claim where aggregate limits apply, audit tests of the data will reveal to what extent limit ceilings have been reached, and in what respect reserve projections may have to be modified to take this factor into account.

\section{Collateral Sources}

For a proper evaluation of a company's total reserve position, the potential impact of salvage and subrogation on the group of claims under consideration should be evaluated even though statutory accounting may prohibit a deduction from loss reserves. In addition, the impact of coinsurance, deductibles, coordination of benefits, second injury fund recoveries, as well as any other collateral sources should be considered.

\section{Reinsurance}

The actuary should know and consider the types of reinsurance plans and retentions currently in force. To the extent that current arrangements might differ from plans in effect during the claim experience period, the actuary should estimate the effect such differences might have on observed emergence and development patterns.

\section{Pools and Associations}

The reserve liability within an insurance company depends in some degree on forces beyond its control, such as business obtained through participation in both voluntary and non-voluntary underwriting pools and associations. 
Nevertheless the actuary should be aware that the operating and reserving policies and loss development patterns of such entities may vary and therefore should be reviewed to determine if adjustments to reported reserves are warranted.

\section{Operational Changes}

It is the actuary's responsibility to review the applicability of existing procedures to current business and to verify the continued applicability of past assumptions to current operations of the company. The installation of a new computer system, an accounting change, a reorganization of claims responsibility or a change in an underwriting program in a company can affect the continuity of the loss experience. When such changes are observable and measurable, appropriate compensating adjustments should be made in the procedures for calculating reserves.

\section{Changes in Loss Distribution}

Losses may occur in all size ranges. Changes in contract provisions may limit or change the amount of actual claim against the insurance company through the use of deductibles, policy limits or the sale of excess coverage which excludes all of the primary layer of losses. Such contractual changes affect both the frequency and severity of actual claims. If the change has been occurring over time, such as in the case of a higher deductible being sold for a particular class of policies, attempts should be made to adjust past experience to reflect current circumstances.

\section{External Influences}

Due regard should be given to the impact of external influences. Specific considerations include the judicial environment, regulatory and legislative changes, residual or involuntary market mechanisms, and economic variables such as inflation.

\section{Reasonableness}

The actuary has a responsibility to consider the reasonableness of the indications produced by the reserving procedures employed. The incurred losses implied by the reserves should be measured against relevant parameters, such as premiums, exposures or number of policies, and expressed wherever possible in terms of frequencies, severities and loss ratios. No material departure from past results should be accepted without attempting to find an explanation for the variation.

A review of the foregoing considerations with regard to a specific insurance product will assist the actuary in the selection of appropriate reserve methods and in the effort to organize claim data properly. 
It is not sufficient for the actuary merely to apply historical analytical procedures in the calculation of reserves. Whenever the impact of internal or external changes on claim data can be isolated or reasonably quantified, adjustment of the data is warranted before applying various reserving methods. Whenever possible, the underlying assumptions of each method should be tested statistically. It may be possible to adjust historical data so that the underlying assumptions of a method are more nearly satisfied.

\section{PROCEDURES}

Loss reserving has two major aspects. First, claim data must be properly organized and controlled. Second, a statistically sound method of estimating the ultimate: cost of losses currently unpaid must be selected to analyze the data.

\section{Data Organization}

As previously mentioned, claim data should be organized into homogeneous groupings. Obtaining homogeneous groupings requires refinement of the data base. Such refinement might entail categorizing claims by line of business, class or geographic location. Generally speaking, refinement that increases homogeneity increases the credibility of the data. On the other hand, excessive fragmentation tends to decrease credibility by depriving individual groupings of enough data to be meaningful.

The categorization of claims by time unit is extremely important. The successful organization of a data base for reserving revolves around four key dates:

1. accident date, which is the date on which the loss occurred or, for those losses which cannot be identified with a single isolated event, the date on which the loss is deemed to have occurred;

2. report date, which is the date on which the loss was first reported to the company (in practice it is usually taken to be the date on which the loss was first entered in the statistical records of the company);

3. accounting date, which is the calendar date selected for an accounting or statistical purpose; and

4. valuation date, which is the calendar date as of which the loss reserve is evaluated.

Claims with report dates equal to or prior to a particular accounting date would be classified as known or reported claims with respect to the accounting date, but claims with report dates later than a particular accounting date and with accident dates equal to or earlier than the accounting date would be classified as IBNR with respect to the accounting date. 
The preceding paragraph gives the precise but narrow definition of IBNR made in Section I. Unfortunately, some confusion exists regarding what the proper definition of IBNR should be. A more liberal definition is often used in which IBNR denotes a provision for both late reported claims and future development on known claims.

The confusion regarding the definition of IBNR can result from the differing strategies companies may employ in approaching the loss reserve problem. There are two principal strategies, and each leads to a preference for a particular method of organizing claim data, which can in turn lead to the particular definition of IBNR that is used.

All companies compile claim data by accident period (accident year, accident quarter, accident month, etc.) i.e. all claims with accident dates falling within a particular fiscal period are grouped together. Claim information by accident year is required for various Annual Statement schedules.

Many companies also compile claim data by report period, which requires that all claims with report dates falling within a specified fiscal period be grouped together.

The two principal strategies usually employed are the report period approach and the accident period approach. When a report period approach is used, an attempt is made to measure the upward or downward development on claims which have already been reported to the company and to use that measurement to estimate the aggregate reserve redundancy or deficiency on those claims. To determine IBNR, additional analysis by accident period is required in order to measure the emergence of IBNR.

When a pure accident period approach is used, report dates are ignored and an attempt is made to estimate directly the ultimate cost of all claims, whether reported or not, arising from accident periods prior to the valuation date. This approach results in an estimate of the total loss reserve. The total loss reserve is then apportioned between reserves for IBNR and known claims on a suitable basis.

The use of accident period techniques can, under certain circumstances, lead to a seemingly broader definition of IBNR than is used in this statement of principles. If, for instance, an accident period approach has been used to estimate directly the total loss reserve and IBNR is obtained simply by subtracting the case reserve from the total, the provision for future development on known claims will automatically be included with IBNR. In these circumstances the provision for reopened claims will also be included with IBNR.

The method of assigning report dates to reopened claims can also lead to confusion in the treatment of such claims for reserving purposes. Because reopened claims are generated from claims previously reported and closed, it is generally agreed that the provision for this liability should, by definition, be included with the reserve for known claims. 
Some companies, however, consider the reopened claim reserve to be part of the IBNR reserve. Instead of recording the original report dates for reopened claims, new report dates are established by these companies. Since the report date determines the distribution of claims between known and unknown, reopened claims will take on the appearance of IBNR claims in the data used in the calculation of the IBNR reserve.

\section{Loss Reserving Techniques}

Detailed discussion of the technology and applicability of current loss reserving practices is beyond the scope of this statement. Selection of the most appropriate method of reserve estimation is the responsibility of the actuary. A competent actuary will ordinarily examine the indications of more than one method before arriving at an evaluation of an insurer's reserve liability for a specific group of claims.

Many useful works are available in actuarial and insurance accounting literature. Notable examples are contained in the reading list that follows this section. The reading list is not all inclusive. Some actuaries may be using valid techniques that are not documented in the literature.

It should be kept in mind that the definitions used in this statement are not necessarily consistent with the implied definitions in some of the articles contained in the reading list.

SUPPLEMENTAL REAIING LIST

\section{General Readingr}

[1] Ruth Salzman, "Estimated Liabilities for Losses and Loss Adjustment Expenses", Chapter 3 of Robert Strain's Property Liability Insurance Accounting, published for IASA (Insurance Accounting and Statistical Association) by The Merrit Company Insurors Press Products.

This chapter reduces reserving procedures to their basic elements. It also identifies and describes various quantification methods in general terms. Pages 29 to $4^{8}$ are particularly applicable.

[2] David Skurnick. (1973). A Survey of Loss Reserving Methods, PCAS (Proceedings of the Casualty Actuarial Society), 60, 16.

This article, which covers both loss reserving and loss adjustment expense reserving, is a comprehensive and definitive survey, with commentary, of the important material published on reserving since 1933 .

[3] Mrchelbacher, F. G. and N. R. Roos (197o). Multiple-Line Insurers, Their Nature and Operations, 181-202, McGraw-Hill Book Company.

This is a general text recommended by the Casualty Actuarial Society as study material for its examinations.

\section{Casualty Actuarial Society}

Most articles appearing in the Proceedings of the Casualty Actuarial Society (PCAS) are reviewed in the same volume or in the following volume by one or more members of the Society.

The following articles are considered to include all discussions, although the page references refer only to the article. 
L1] BalCARek, R. J. (1961). Reserves for Reopened Claims on Workmen's Compensation, PCAS, 68, 1 .

[2] BalCarek, R. J. (1966). Effect of Loss Reserve Margins in Calendar Year Results, $P C A S, \mathbf{5 2}, 1$.

This paper is not intended to describe a specific procedure or practice. It is intended to show the effect that haphazard variations in reserve adequacy can have on underwriting results.

[3] Berquist, J. R. and R. E. Sherman (1978). Loss Reserve Adequacy Testing: A Comprehensive, Systematic Approach, $P C A S, 65$.

[4] Bornhuetter, R. L. and R. E. Ferguson (1972). The Actuary and IBNR, PCAS, $59,181$.

[5] Ferguson, R. E. (1971). Actuarial Note on Workmen's Compensation Loss Reserves, $P C A S, 58,51$.

FERGUSON's paper is concerned with the proper use of annuity functions in determining the correct apportionment of Workmen's Compensation annuity type reserves between reinsurer and reinsured.

[6] Fisher, W. H. and J. T. Lange (1973). Loss Reserve Testing: A Report Year Approach, $P C A S, 60,189$.

[7] Fisher, W. H. and E. P. Lester (1975). Loss Reserve Testing in a Changing Environment, $P C A S, 62,154$.

[8] Harwayne, F. (1958/1959). Estimating Ultimate Incurred Losses in Auto Liability Insurance, $P C A S, 45,63$, and Some Further Notes on Estimating Ultimate Incurred Losses in Automobile Liability Insurance, $P C A S, \mathbf{4 6}, 59$.

Although not concerned specifically with loss reserving, Harwayne's articles illustrate a mathematical approach to estimating ultimate claim costs.

[9] McClenahan, C. L. (1975). A Mathematical Model for Loss Reserve Analysis, $P C A S, 62,134$.

[10] Resony, A. V. (1972). Allocated Loss Expense Reserves, PCAS, 59, 141.

[11] Simon, L. J. (1970). Distortion in IBNR Factors, $P C A S, 57,64$.

SIMON's paper deals with the problem of estimating IBNR when exposures are expanding rapidly.

[12] TAPley, D. A. (1956). Month of Loss Deficiency Reserves for Automobile Bodily Injury Losses Including Reserves for Incurred But Not Reported Claims, PCAS, 63, 166 .

[13] Tarbell, T. F. (1971). Incurred But Not Reported Claim Reserves, PCAS, 20, 1933, 275. Reprinted in PCAS, 58, 83 .

\section{Insurance Accounting and Statistical Association}

[1] Brian, R. E. (1967). Formula Reserving for Loss Expense, PIASA (Proceedings of the Insurance Accounting and Statistical Association), 498.

[2] Petz, E. F. (1974). Testing and Evaluating Loss Expense Reserves, PIASA, 693.

[3] Sampson, R. D. (1959). Establishing Adequacy of Reserves on Slow Closing LinesUse of Paid Loss Formulae, PIASA, 306.

[4] Scheiber, J. E. (1970). Developments in Formula Reserving Methorlology, PIASA, $55^{\circ}$.

[5] Singer, P. E. (1959). IBNR Reserves Including Reopened Cases, PIASA, 240.

[6] Slifka, R. S. (1968). Testing of Loss Adjustment (Allocated) Expense Reserve, PIASA, 291.

\section{Society of Actuaries}

Articles appearing in the Transactions of the Society of Actuaries (TSA) include all discussions in the same or subsequent volumes, although page references refer only to the article.

[1] BragG, J. M. (1964). Health Insurance Claim Reserves and Liabilities, TS $A, 16,17$. 